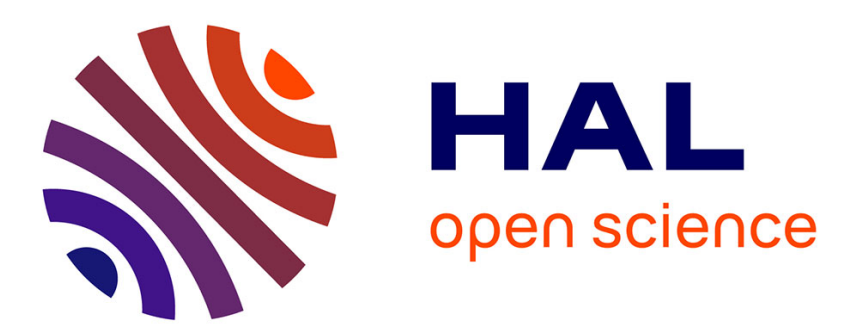

\title{
The stripline coupling of thin-film josephson junctions to external circuits at microwave frequencies
}

\author{
Y. Sirkeinen, P. Somervuo, T. Wiik
}

\section{To cite this version:}

Y. Sirkeinen, P. Somervuo, T. Wiik. The stripline coupling of thin-film josephson junctions to external circuits at microwave frequencies. Revue de Physique Appliquée, 1974, 9 (1), pp.131-133. 10.1051/rphysap:0197400901013100 . jpa-00243722

\section{HAL Id: jpa-00243722 https://hal.science/jpa-00243722}

Submitted on 1 Jan 1974

HAL is a multi-disciplinary open access archive for the deposit and dissemination of scientific research documents, whether they are published or not. The documents may come from teaching and research institutions in France or abroad, or from public or private research centers.
L'archive ouverte pluridisciplinaire HAL, est destinée au dépôt et à la diffusion de documents scientifiques de niveau recherche, publiés ou non, émanant des établissements d'enseignement et de recherche français ou étrangers, des laboratoires publics ou privés. 


\title{
THE STRIPLINE COUPLING OF THIN-FILM JOSEPHSON JUNCTIONS TO EXTERNAL CIRCUITS AT MICROWAVE FREQUENCIES
}

\author{
Y. SIRKEINEN, P. SOMERVUO and T. WIIK \\ Helsinki University of Technology, EE Dept., SF-02150 Otaniemi, Finland
}

\begin{abstract}
Résumé. - Nous avons étudié une façon particulière de coupler une jonction Josephson en couche mince. Une structure supraconductrice en "strip-line » se terminant au bord de la jonction $\mathrm{Nb}$-oxyde- $\mathrm{Pb}$, assure le couplage. Une désadaptation de $23 \mathrm{~dB}$ entre le générateur et la jonction a été obtenue en bande $X$; ce résultat doit être comparé avec les estimations précédentes d'une désadaptation de $40 \mathrm{~dB}$ entre les circuits de sortie conventionnels et la jonction. De bonnes perspectives d'amélioration du couplage sont en vue. On donne des méthodes pour évaluer la tension et la puissance couplées à la jonction.
\end{abstract}

\begin{abstract}
A certain way of coupling to the thin-film Josephson tunneling junction has been studied. The coupling structure comprises a superconducting stripline which is terminated to the edge of the $\mathrm{Nb}$-oxide- $\mathrm{Pb}$ junction. A mismatch of $23 \mathrm{~dB}$ has been obtained so far between the signal source and the junction at X-band compared to the earlier estimates of $40 \mathrm{~dB}$ between conventional size outer circuits and the junction. Prospects for improving the coupling are good. Methods of estimating the voltage and power which are coupled to the junction are given.
\end{abstract}

1. Introduction. - Usually the thin-film type Josephson junction [1] is considered to be rather unsuitable for most potential applications in the microwave frequency range. This arises from the large junction capacitance taken as a lumped element. It is typically of the order of hundreds of picofarads, which will shunt all active phenomena of interest in the junction. For this reason only a few attempts to couple the tunnel junction efficiently to an outer circuit have been reported [2], [3]. It has become common to speak of a $40 \mathrm{~dB}$ mismatch between the junction and free space (or e. g. a waveguide) [4]. In a variety of possible applications, such as mixers, detectors and amplifiers, the strength of the coupling is, however, of great importance.

Here we consider the tunnel junction as a superconducting transmission line resonator, which of course still leaves us the problem of coupling to a very low impedance.

In this work a certain type of coupling of a thinfilm tunneling junction to outer circuits has been studied. Despite their narrow bandwidth capability and difficult coupling tunnel type junctions have been examined mainly because of experience in their reliable fabrication. The electrical and mechanical stability of the junctions has to be emphasized, too.

2. Fabrication of the junctions. - The junctions are made by evaporating crossed strips of superconductive material through metal masks on a glass substrate. The bottom strip is niobium and it is evaporated to a thickness of appr. $200 \mathrm{~nm}$. The junction dielectric barrier is produced by plasma discharge oxidation of niobium. The obtainable critical current densities of the junctions vary between $1 \mathrm{~mA} / \mathrm{mm}^{2}$ and $1 \mathrm{~A} / \mathrm{mm}^{2}$. To complete the junction a lead strip of thickness 200 to $400 \mathrm{~nm}$ is evaporated which crosses the niobium strip perpendicularly.

The superconducting stripline structure which is used to the coupling of microwave frequencies is produced at first by further oxidation of the niobium strip. The oxide thickness is of the order of $20 \mathrm{~nm}$. On the oxide dielectric finally a lead film is deposited, figure 1, which has the proper shape of quarterwavelength transformers, i. e. the strip width is used to change the line impedance. The lead strip is either etched by means of photoresist technique or evaporated through a metal mask. The latter method has proved to be more reliable in producing very narrow strips. Widths of the order of $10 \mu \mathrm{m}$ have been obtained with fair reliability.

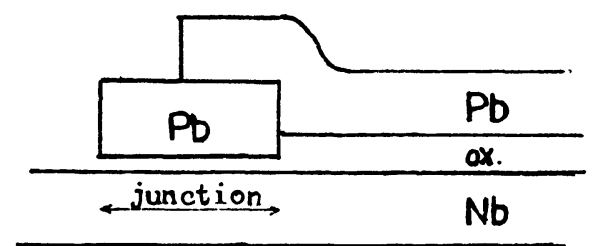

Fig. 1. - Side view of the junction and stripline structures.

During the oxidation of niobium apparently only a very thin layer of lead oxide, if any at all, is formed on the surface of the lead strip. Another possibility is that the lead oxide is unstable and vanishes before any measurements have taken place. Thus a (practically) galvanic contact between the two lead films exists. 
As a result a superconducting stripline circuit is achieved which terminates to a tunneling junction, figure 1. To prevent any contamination or further oxidation of the evaporated materials a thin coating of lacquer is deposited or a film of $\mathrm{SiO}$ is evaporated. The latter shielding has proved to be more resistant to thermal cycling than the lacquer. The junctions are electrically stable and tolerate repeated cooling without any noticeable deterioration. The reproducibility of the junctions is fairly good.

3. The coupling circuit. - The coupling from an outer circuit is performed by using a superconductive quarter-wavelength transformer chain, figure 2. The substrate is placed partly inside a waveguide through a narrow slit in the waveguide broad side wall. At the end of the stripline the bottom strip is broadened to give a good rf-contact to the waveguide wall. The upper strip extends to the interior of the waveguide forming an antenna. The radiation impedance of the antenna has obviously a considerable reactive part because of the thinness of the strip. The waveguide is terminated to a movable short for tuning purposes.

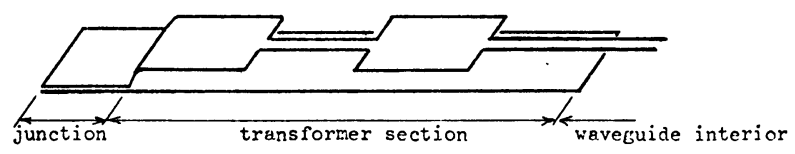

FIG. 2. - Schematic representation of the coupling structure.

The wavelength in a general superconductive stripline is known to obey [5]

$$
\lambda_{\mathrm{r}}=\lambda_{0} \sqrt{\frac{l}{\varepsilon_{\mathrm{r}} d}}
$$

where $\lambda_{0}$ is the free space wavelength, $\varepsilon_{\mathrm{r}}$ and $l$ are the relative permittivity and the thickness of the oxide barrier and $d=2 \lambda_{\mathrm{L}}+l$, where $\lambda_{\mathrm{L}}$ is the London penetration depth.

The characteristic impedance of a superconductive stripline is

$$
Z_{\mathrm{c}}=Z_{0} \frac{\sqrt{l d}}{w \sqrt{\varepsilon_{\mathrm{r}}}}
$$

where $Z_{0}$ is the characteristic impedance of free space and $w$ is the strip width.

Typical values of $w$ have been 10 to $300 \mu \mathrm{m}$ and $d$ is roughly $0.1 \mu \mathrm{m}$. The relative permittivity of the niobium oxide is believed to be appr. 20 at X-band frequencies and liquid helium temperatures [6]. This value is also supported by our own observations.

Eq. (2) holds also for the junction in at least two important limiting cases. The first one is the large signal limit, where the nonlinear Josephson current which is limited in amplitude to the critical current density $j_{1}$, may be neglected compared to the other (normal) currents in the junction. The other, and more important one, is the small signal limit in the case of zero dc bias voltage when there are no mixing products and all harmonics of the signal frequency are comparatively small in amplitude and may be excluded.

Furthermore, one has to assume that the cosine of the wavefunction phase difference $\varphi$ is small enough or that the frequency $\omega$ is high enough to permit wave propagation in the junction, which is stated in the well known dispersion equation for the wave number

$$
k^{2}=\frac{\omega^{2}}{c_{r}^{2}}-\frac{\cos \varphi}{\lambda_{J}^{2}} .
$$

Here $c_{\mathrm{r}}=\omega \lambda_{\mathrm{r}} / 2 \pi$ and $\lambda_{\mathrm{J}}$ is the Josephson penetration depth [1].

If the point of operation is on the top of a current step, we have $\varphi=\pi / 2$ and the propagation is dispersionless and also the eq. (1) holds in the junction.

If the junction is assumed to have sufficiently low losses, the real part of its input impedance can be given in the form

$$
R_{\mathrm{in}}=\frac{2 Q_{0}}{\pi} Z_{\mathrm{c}}
$$

at the first half-wave resonance, which should on the other hand give the best coupling. Here $Q_{0}$ is the unloaded $Q$-value of the cavity formed by the junction and the eq. (2) is assumed to be valid, as stated above.

The general input impedance for the junction in the active nonlinear region is very complicated and strongly dependent on both the dc bias voltage and the signal frequency and amplitude [7], but it will be left aside in this context.

The eq. (4) may be used as a reasonable dimensioning criterium, although its actual validity is limited.

4. Detection of microwave signals. - Depending on the electrical length of the junction and the transformer sections coupling of power from the outer circuit to the junction will result. The amount of power which is coupled may be estimated by the aid of the known Bessel function obeying behaviour of the constant voltage steps which are induced to the junction $I-V$ characteristic. It is especially feasible to observe the effect which the signal has on the zeroth step, i. e. the maximum current of the junction.

Since the dielectric barrier is open-ended a standing wave pattern of the form $V_{\mathrm{m}} \cos (\beta z)$ for the voltage is a reasonable assumption, where $V_{\mathrm{m}}$ stands for maximum voltage amplitude. From the Josephson equations [1] it is known that a combination of dc and sinusoidal biasing voltages will affect the supercurrent density according to

$$
j=j_{1} \sum_{n} J_{n}\left(\frac{2 \mathrm{e} V(z)}{\hbar \omega}\right) \sin \left(\varphi+\omega_{0} t+n \omega t\right)
$$

where $\omega_{0}$ corresponds to the dc bias voltage. $V(z)$ and $\omega$ are the voltage amplitude and the frequency 
of the ac bias. If the external magnetic field is small and the length of the junction less than about $2 \lambda_{\mathrm{J}}$, then the phase $\varphi$ is constant along the junction. Taking the dc-component of the current and maximising it $(\varphi=\pi / 2)$ will give an equation for the maximum current

$$
I_{\mathrm{m}}=j_{1} w \int_{0}^{L} J_{0}\left(\frac{2 \mathrm{e} V_{\mathrm{m}}}{\hbar \omega} \cos (\beta z)\right) \mathrm{d} z .
$$

Here $L$ is the junction length.

If the excitation is small, the effect of voltages at harmonic frequencies of $\omega$ excited through (5) may be neglected. Then also $J_{0}$ may be succesfully expanded to a power series of $\cos (\beta z)$, which is easy to integrate. Thus, by measuring the decrease in the critical current, an equation is obtained for the unknown $V_{\mathrm{m}}$.

The power which is coupled to and dissipated in the junction may be calculated using the standard equation

$$
P=\frac{w}{2} \int_{0}^{L} \sigma\left(V_{\mathrm{m}} \cos (\beta z)\right)^{2} \mathrm{~d} z=\frac{\pi}{4 Q_{0} Z_{\mathrm{c}}} V_{\mathrm{m}}^{2} .
$$

In the latter, the conductivity $\sigma$ has been assumed to be independent of the voltage and has been expressed in terms of the junction $Q$. The case of half-wave resonance has also been assumed.

Another procedure to find out the strength of coupling may also be stated. Using the known properties of high-order constant argument Bessel functions, taking eq. (5) and the standing wave voltage pattern into account it is relatively easy to show [8] that the voltage amplitude $V_{\mathrm{m}}$ is given by

$$
V_{\mathrm{m}}=\frac{\hbar \omega}{2 \mathrm{e}} z_{1, n}
$$

Here $z_{1, n}$ is the first zero of $J_{n}$ and $n$ is the highest step number for which there is a local maximum observable in the step height envelope. The signal power is again given by eq. (7). This method is applicable to other types of junctions as well.
5. Experimental results. - At the present stage of experiments only a few junctions have been tested. The junctions have had different dimensions and critical currents. The best results by now show that a mismatch of $23 \mathrm{~dB}$ has been achieved between the signal source and the junction by using eq. (8). The agreement between the two methods via eq. (6) and eq. (8) was within a few $\mathrm{dB}$ in some cases somewhat higher in some others most evidently because of violation of the assumption of constant $\varphi$ over the junction (eq. (5), (6)). Junction $Q$-values given by Pedersen et al. [9] have been assumed. The $Q$-values are inversely proportional to the junction critical current and are of the order of $10 \ldots 20$ in our cases. Microwave induced steps have been clearly observable in the $I-V$ characteristics up to $n=130$ at a frequency of $6.8 \mathrm{GHz}$.

It is believed that a great deal of the problems in this type of coupling would be overcome with sufficient knowledge of the permittivity and most of all the thicknesses of the oxide layers. The coupling may obviously be improved further e. g. by the broadband tapering of the stripline or by making the transformer and junction resonant frequencies coincide, which most probably was not the situation. By making the junction extremely narrow its input impedance may increase notably, perhaps to a level where no transformer chains will be needed.

6. Conclusions. - A coupling to the thin-film tunneling junction has been studied in which a superconducting stripline is terminated to the edge of the junction. Results show that the method is promising although a relatively large mismatch still exists.

Acknowledgments. - The valuable assistance of Mrs. Leena Korhonen in preparing the junctions and also the grants from the foundations Tekniikan Edistämissäätiö, Alfr. Kordelinin säätiö and Kaupallisten ja teknillisten tieteiden tukisäätiö are deeply appreciated.

\section{References}

[1] Josephson, B. D., Phys. Lett. 1 (1962) 251 ; Rev. Mod. Phys. 36 (1964) 216 ; Adv. Phys. 14 (1965) 419.

[2] Owen, C. S., Scalapino, D. J., J. Appl. Phys. 41 (1970) 2047.

[3] Coon, D. D., Fiske, M. D., Phys. Rev. 138 (1965) A 744

[4] Langenberg, D. N., Scalapino, D. J., Taylor, B. N., Proc. IEEE 54 (1966) 560.

[5] Swihart, J. C., J. Appl. Phys. 32 (1961) 461.
[6] Bondarenko, S. I., Dmitrienko, I. M., Narbut, T. P., Sov. Phys. Solid State 14 (1972) 295.

[7] Auracher, F., Van Duzer, T., J. Appl. Phys. 44 (1973) 848.

[8] Somervuo, P., Sirkeinen, Y., to be published.

[9] Pedersen, N. F., Finnegan, T. F., Langenberg, D. N., Phys. Rev. B 6 (1972) 4151. 